\title{
ENTRE A TRADIÇÃO E A MODERNIDADE, OS POTIGUARA. ESTUDO ETNO-HISTÓRICO, NARRATIVAS DE MEMÓRIA E RITUAIS, A REVISITAÇÃO E O TURISMO
}

\author{
BETWEEN TRADITION AND MODERNITY, THE POTIGUARA. \\ ETHNO-HISTORICAL STUDY, NARRATIVES OF MEMORY AND \\ RITUALS, REVISITING AND TOURISM
}

\begin{abstract}
José Manuel Simões
Professor da Universidade de São José, Macau, China Doutor em História pela Universidade de São José, Macau, China e-mail: jmsimoes@usj.edu.mo

DOI:

http://dx.doi.org/10.26512/hh.v5i10.11000

Recebido em 13 de setembro de 2017

Aprovado em 02 de dezembro de 2017

\section{RESUMO}

Abrindo a nossa observação etno-histórica dos lugares da memória dos índios Potiguara, seus símbolos, práticas tradicionais e festas colectivas, percebemos que esses lugares da memória são o que nos chega, fica, seleciona o passado. Os rituais que os Potiguara apresentam como museus e mostruários da sua cultura singular, remetem imediatamente para a formação dessa outra comunicação tão primária na formação de culturas colectivas que é o do som e da música que se vai, depois, verter em festa. Não existindo documentação histórica e evidências etnográficas suficientes para investigar com rigor a formação cultural da música e das festas tradicionais entre os Potiguara, não existe outro caminho a não ser o de procurar observar densamente os grandes festivais colectivos que os Potiguara continuam a oferecer como tradicionais e representativos da sua cultura, dando destaque neste estudo aos rituais dos cocos que devem ter entrado nos espaços indígenas litorais do Brasil com a colonização económica da cana-de-açúcar que, entre os séculos XVII e XIX, se foi alimentando da massiva importação de mãode-obra escrava africana, espalhando-se com colonizações, missionações e transformações das festas regionais e locais dos espaços rurais brasileiros.
\end{abstract}

Palavras-chave: Potiguaras; memória; turismo

\begin{abstract}
Opening our ethno-historical observation of the places of memory of the Potiguara Indigenous people, their symbols, traditional practices and collective celebrations, we realize that these places of memory are what arrives at us, stays, selects the past. The festivals that the Potiguara present as museums and showcases of their singular culture, immediately refer to the formation of this other communication so primary in the formation of collective cultures: the sound and music that is then to be sung in celebration. As there is no historical documentation and enough ethnographic evidence to rigorously investigate the cultural formation of music and traditional festivals among the Potiguara, there is no other way than to look densely at the large collective festivals that the Potiguara continue to offer as traditional and representative of their culture, emphasizing in this study the rituals of the "coco" that must have entered at the indigenous coastal spaces of Brazil with the economic colonization of the sugar cane that, between the XVII and XIX centuries, was fed by the massive importation of African
\end{abstract}


slave labor, spreading with colonizations, missionaries and transformations of the regional and local festivals of Brazilian rural spaces.

Keywords : Potiguras; memory; tourism

\section{INTRODUÇÃO}

Os vários volumes coordenados por Pierre Nora para perseguirem uma história dos lugares da memória da França tornaram-se em referência teórica multidisciplinar para quem, como nós, procura reconstruir essa outra história das memórias com que se organiza hoje a representação do que se quer ser uma cultura Potiguara, assim denominados os índios que desde o século XVI habitavam parte do litoral do Nordeste do Brasil, aproximadamente entre as atuais cidades de João Pessoa, na Paraíba, e São Luís, no Maranhão. Os últimos assumidos remanescentes provavelmente de um território cultural antes bem mais vasto vivem atualmente nos municípios de Baía da Traição, Marcação e Rio Tinto, no litoral setentrional da Paraíba.

$\mathrm{Na}$ introdução ao volumoso trabalho que dirigiu durante oito anos, Nora explicava o seu entendimento epistémico da noção de "lugares da memória", sublinhando que um "lieu de mémoire" é qualquer entidade significativa que, material ou imaterial por natureza, através da vontade humana ou do desgaste do tempo, se tornou um elemento simbólico da herança memorial de uma comunidade. Acrescentava ainda o historiador francês que, sendo a memória a estrutura fundamental deste processo geralmente demorado, convinha entendê-la como um fenómeno de emoções e magias que apenas acomoda os factos que a alimentam. Em rigor, a memória é sempre vaga, reminiscente, agita tanto impressões gerais quanto finos detalhes simbólicos. Mais ainda, a memória é sempre vulnerável a transferências, recordações reprimidas e imaginadas, a censuras e a todo o tipo de projeções. ${ }^{1}$

Os lugares da memória são também quase sempre o que nos chega, fica e seleciona o passado. Uma estátua aqui, um nome de rua acolá; um desfile cívico ou uma celebração religiosa; um prato, um sabor, cores, paisagens tanto como essas recordações de viagens turísticas multiplicando fotografias, vídeos, magnetes ou peças que se acredita serem genuinamente tradicionais e originais. Os nossos índios Potiguara, como veremos mais à frente, já se renderam com benefícios materiais à demanda turística, restando saber se os seus diferentes lugares da memória ainda selecionam tradições do passado ou decidiram

${ }^{1}$ NORA, Pierre. Les Lieux de mémoire. Tomo I. v. 7. Paris: Gallimard, 1984. 
definitivamente projetar recordações cada vez mais vagas, reminiscentes e, por isso, progressivamente mais imaginadas. Paralelamente, este é também o andamento de investigação em que, para além dessas personalidades mais dominantes de caciques, pajés, curandeiras e dissidentes, encontraremos a comunidade, o Potiguara "comum" e as suas manifestações culturais colectivas que insistentemente apresentam ligadas à sua singular memória colectiva.

\section{OBSERVAÇÃO ETNO-HISTÓRICA DOS LUGARES DA MEMÓRIA}

Comecemos por abrir a nossa observação etno-histórica dos lugares da memória Potiguara estudando com atenção esses espaços que ainda aparecem hoje carregados de símbolos e práticas tradicionais: as festas colectivas. Os grandes festivais que os Potiguara apresentam como museus e mostruários da sua cultura singular - o coco e o toré - remetem imediatamente para a formação dessa outra comunicação tão primária na formação de culturas colectivas que é o do som e da música que se vai, depois, verter em festa. Caso creditemos alguma autoridade científica às pesquisas e textos célebres de Le Clézio, seríamos convidados a entender a música dos índios brasileiros como uma produção de gritos e de ruídos que, tal como nos "primórdios", remeteria dupla e paradoxalmente para a imitação e ruptura com o mundo dos animais:

\footnotetext{
Música sem melodia, sem harmonia. Música, não para dançar, não para agradar, mas sim para falar, gesticular, para chamar. Música também para afastar, para manter à distância. A música não é o contrário do silêncio, é o seu complemento. Quando o índio toca música, esconde-se, porque a música, sabe-o ele, expõe-no ainda mais perigosamente do que a linguagem. Gritos e ruídos vindos das profundezas, de súbito o homem volta a ser igual às outras criaturas, que não falam mas murmuram. E ao mesmo tempo, $\mathrm{e}$ porque organiza estes ruídos, o índio afasta-se definitivamente do reino animal, torna-se um dos criadores do universo. ${ }^{2}$
}

Não se trata nesta interpretação de uma ideia absolutamente original quando se procuram convocar competências científicas nos domínios complexos da etno-génese e formação de espaços culturais. Uma das teses mais importantes nestes campos muito problemáticos e fluidos continua a ser essa obra tão inteligente quanto esquecida que o grande

${ }^{2}$ LE CLÉZIO, J.M.G. Índio Branco. Lisboa: Fenda Edições, 1989, p. 47-48.

Revista história, histórias, volume 5, número 10, ago. dez. 2017 
historiador da Idade Média, Johan Huizinga, intitulou Homo Ludens ${ }^{3}$. Investigando a relação entre jogo e cultura, entre divertimento e práticas culturais, Huizinga explicou o primado causal do jogo, da brincadeira, que, aprendida pelo homem na observação do natural e dos animais, se tornava factor formativo das culturas como se podia testemunhar em muitos mitos antigos. ${ }^{4}$ Infelizmente, não se recolhem atualmente entre os Potiguara mitos e legendas arcanos mais completos do que os fragmentos memoriais que se informam nas conversas com esses líderes políticos e espirituais que são caciques, pajés e curandeiros. Fica difícil perceber através da agenda de investigação de Huizinga como é que o jogo e o divertimento entre os Potiguara foi produzindo práticas e hábitos culturais organizados. Os seus sons e músicas ainda permanecem hoje como uma das principais pontes que ligam ao passado. Mas que é um passado - outra vez - sobretudo colonial.

$\mathrm{Na}$ verdade, o que ainda sabemos da história e antropologia da música entre as diferentes culturas ameríndias pré-coloniais do Brasil aparece-nos, como em muitas outras áreas sociais, culturais e religiosas intermediada pelos relatos dos missionários católicos. Assim, numa perspectiva panorâmica, as investigações geralmente competentes do historiador RusellWood esclarecem que

ainda que pouco documentadas para o período pré-colonial e colonial inicial, evidências limitadas e analogias etnográficas sugerem que os índios tinham uma grande variedade de instrumentos musicais, com uma preferência pelos instrumentos de sopro, como as flautas. Os jesuítas testemunharam as excelentes qualidades corais dos índios, mas a sua música parece ter sido bastante limitada, com a repetição monótona de um único refrão ou de alguns ritmos derivados do canto dos pássaros e da natureza. Os jesuítas reconheceram a aptidão dos índios para a música mas, em lugar de lhes permitirem desenvolver a sua própria cultura, usaram a música como um instrumento para atingir o controlo. Apresentaram-lhes novos instrumentos europeus como o cravo, e ensinaram-lhes cânticos em latim e em português. Como resultado, as tradições musicais índias apenas sobreviveram longe dos centros de atividade portuguesa, ainda que no século XIX Carlos Gomes tenha recorrido a fontes índias para inspiração para a sua ópera $O$ Guarani, como também o fez o compositor Heitor Vila-Lobos no século XX. Antropólogos e etnógrafos demonstraram que esta tradição ainda está viva, e

${ }^{3}$ HUIZINGA, Johan. Homo Ludens. A Study of the play element of culture. Leiden: Leiden University, 1938.

4 'The view we take in the following pages is that culture arises in the form of play, that it is played from the very beginning... Social life is endued with supra-biological forms, in the shape of play, which enhances its value. (...)"Now in myth and ritual the great instinctive forces of civilized life have their origin: law and order, commerce and profit, craft and art, poetry, wisdom and science. All are rooted in the primeval soil of play." HUIZINGA, 1938, p. 5-6. 
que a música e a dança acompanham todos os eventos e transições importantes nas vidas dos americanos nativos que sobreviveram ao genocídio e ao etnocídio. ${ }^{5}$

Mobilizadas as mentes e as vozes para a fé cristã, tantas vezes pela força brutal, asilados em aldeamentos que se tornaram as fontes históricas das reivindicações atuais de reservas e terras indígenas, os Potiguara souberam, pelo menos, preservar os seus instrumentos musicais tradicionais, optando por continuar a usar canudos de bambu, flauta de dois orifícios, tambores, conchas. Com estes objetos acompanham os seus cantos que se querem próximos do som emitido pelas aves, pelos macacos, pelo bem-te-vi, pelo beija-flor, pelo gavião, pela serpente. A linguagem destas vozes ou cantos é repetitiva e próxima da reza, da oração, remetendo os Potiguara para o mundo ctónico dos seus antepassados. Vozes ou cantos que, mais do que divertimento, são uma forma dos índios se aproximarem dos deuses, dos seus antepassados, da natureza, como se através deles os Potiguara pudessem compreender, controlar e dominar o seu locus através de batalhas cantadas contra os espíritos, o desconhecido, o oculto, afastando o mal e os perigos, infirmando todas as dificuldades. Vozes e cantos que são sobretudo essas rezas e orações que descobrimos entre pajés e curandeiros ou nos grandes festivais colectivos.

Sempre que estas vozes, cantos e orações convocam um instrumento musical predomina a flauta de cana. São normalmente três as notas sopradas nesta flauta, criando um som adequado às estruturas repetitivas das orações. Os graves e os agudos unidos são soprados em conjunto criando uma linguagem útil no processo de memorização individual e colectiva: "as flautas e a garganta têm o mesmo nome: chiru, pois o índio as reconheceram como os únicos dignos de entrar em competição com as vozes dos animais". ${ }^{6}$ Em rigor, muito mais do que uma competição com o mundo natural, cantando a sua domesticação, as vozes, cantos e rezas dos Potiguara organizam uma especial relação entre linguagem e música, entre a palavra e a oração. O canto e a música entre os Potiguara não é um mero prolongamento da linguagem ou da palavra, mas uma defesa contra ela, remetendo para a produção de outras vozes e sonoridades:

O espasmo da garganta que produz este tom sobre agudo, frágil murmúrio

${ }^{5}$ RUSSELL-WOOD, A. J. R. Fronteiras no Brasil Colonial. Oceanos, n. 40. Lisboa, p. 19, 1999.

${ }^{6}$ LE CLEZIO, 1989, p. 53. 
mais do que voz, é o próprio sinal no canto (trianbi), mas sim na palavra (fedda); para além, está-se no grito (biavi). Homens, mulheres e crianças cantam com a mesma voz, sem que seja possível distingui-los. O canto não tem o mesmo veículo que a palavra. Utiliza a voz quebrada, a voz irreconhecível. ${ }^{7}$

A formação antropológica desta outra forma de linguagem que se manifesta em cantos e orações é muito difícil de reconstruir. Remete imediatamente para mitos e legendas fundacionais, certamente para os processos de territorialização de linhagens e para a glorificação dos seus heróis, reais ou imaginados, processos praticamente desconhecidos entre os Potiguara. É possível, porém, que estes processos antropoculturais na formação de uma linguagem musical possam ter partilhado o modelo geral sugerido por Natalie Curtis:

Nem todos os cantos são religiosos, mas dificilmente há um evento, grande ou pequeno, que não tenha o seu canto correspondente. Em quase todos os mitos dos índios o criador canta e é pelo seu canto que surge a vida. Verdade, tradição, história e pensamento são preservados no ritual do canto e da poesia. Nele os índios registam os ensinamentos dos seus sábios, os feitos de seus heróis, as visões de seus profetas e o culto de seu Deus. ${ }^{8}$

Não existindo, assim, documentação histórica e evidências etnográficas suficientes para investigar com rigor a formação cultural da música e das festas tradicionais entre os Potiguara, não existe outro caminho a não ser o de procurar observar densamente os grandes festivais colectivos que os nossos índios continuam a oferecer como tradicionais e representativos da sua singular cultura: o toré e o coco.

\section{O COCO: MOSTRUÁRIO CULTURAL}

Se o toré ainda vai sobrevivendo como manifestação cultural tradicional dos Potiguara, pese embora as bandas e os andores, importa saber o que se passa com a outra grande prática festiva da comunidade: o coco. É verdade que o coco mobiliza a música, o canto e a festa Potiguara, mas é quase impossível apresentá-lo como uma manifestação genuína, original e, ainda menos, muito antiga. $\mathrm{Na}$ verdade, desenvolvido essencialmente por descendentes de escravos negros, vários estudiosos apontam a origem africana do coco tanto na estrutura quanto nos instrumentos usados, todos de percussão - ganzá, zabumba ou bumbo, zambê ou

${ }^{7}$ LE CLEZIO, 1989, p. 61-63.

${ }^{8}$ CURTIS, Natalie. The Indian's Book. Dover: New Edition, 1968, p. 24. 
pau furado, caixa ou tarol.

Os cocos devem ter entrado nos espaços indígenas litorais do Brasil com a colonização económica da cana-de-açúcar que, entre os séculos XVII e XIX, se foi alimentando da massiva importação de mão-de-obra escrava africana. Mas não são uma influência direta africana, visto se terem espalhado com colonizações, missionações e transformações das festas regionais e locais dos espaços rurais brasileiros. Por isso, encontramse no coco pontos de contacto com outras manifestações, cruzando-se com a dança da ciranda, surgindo em versos semelhantes aos das quadrilhas de São João e Santo António, ou com os cantos da música tradicional do Nordeste do Brasil, o forró. Mais ainda, o coco não se organiza numa estrutura festiva rígida, abrindo-se já a diferentes combinações de canto e dança já à simples recitação e leitura de uma poesia oral de folhetim:

Os cocos assumem várias feições, podendo configurar-se como canto acompanhado apenas por palmas e batidas dos pés, canto com acompanhamento de pandeiro ou ganzá; só texto escrito, quando integra a literatura de folhetos; dança acompanhada de versos cantados ao som de bumbos, ganzá e outros instrumentos de percussão; cantos integrados a cultos religiosos afro-brasileiros. ${ }^{9}$

Apesar destas raízes que se apresentam, não sem problemas históricos e antropológicos, como afro-brasileiras, o coco parece ter chegado tarde, já pelas primeiras décadas do século XX, às aldeia Potiguara. Com efeito, recenseiam-se estudos sugerindo que o coco entrou apenas no início dos anos de 1920 nas localidades indígenas Potiguara de São Francisco e na vizinha Baía da Traição, como parecem comprovar as recolhas empreendidas por Mário de Andrade. ${ }^{10}$ Mais recentemente, numa pesquisa iniciada em Maio de 1992, Maria Ignez e Marcos Ayala, encontraram coquistas ${ }^{11}$ noutras localidades indígenas Potiguara, principalmente em Jacaré de São Domingos, município de Rio Tinto. Seja como for, essas raízes e cultos que se querem afro-brasileiros não parece terem influenciado a mobilização do coco pelos Potiguara que passaram a preferir utilizá-lo nas grandes festas do calendário

\footnotetext{
${ }^{9}$ AYALA, Maria Ignez Novais; AYALA, Marcos. Cocos, Alegria e Devoção. Natal: EDUFRN, 2000, p. 13.

${ }^{10}$ Mário de Andrade reuniu uma importante fonte de informação através de documentação e da gravação de cocos, tendo entrado em contacto directo com os moradores de diversas localidades da Paraíba, nomeadamente nas terras da reserva, entre os finais de 1928 e Fevereiro de 1929. Iniciou um livro, intitulado "Na pancada do ganzá" que nunca viria a terminar. Todavia, os cocos que recolheu durante a sua investigação e pesquisa constituem até hoje o maior arquivo existente sobre esta temática (V. Cocos do Norte, in: http://ninnoamorim.blogspot.com/2007/08/os-cocos-uma-manifestao-cultural-em-trs_17.html).

${ }^{11}$ Cantores, instrumentistas e dançarinos que se dedicam à manifestação do coco.
} 
litúrgico católico: São João e São Pedro, Santa Ana e, em Janeiro, na época dos chamados, também localmente, Santos Reis. Nestas festividades, os grandes artistas Potiguara não mobilizam apenas um género singular e unificado de coco, oferecendo geralmente três diferentes especializações: coco praieiro, coco de roda e coco de embolada, géneros compartilhando a ironia e o grotesco, a ambiguidade e a crítica social, seja nos cantos ao desafio, seja na canção individual.

Apesar da diversidade de géneros, temas e formas, o coco entre os Potiguara é canção e dança, música e bailado. Nas suas formas mais simples, o coco é tocado apenas com o ganzá - uma lata com sementes no interior. Já as letras do coco de roda excitam o desafio, impõem uma imaginação espontânea e aguçam a curiosidade satírica, como neste exemplo que decidiram dedicar-me: "Mineiro palmeirô vou-me embora para Recife/ Mineiro palmeirô não sei quando chego lá/ Mineiro palmeirô lá tenho um bom amigo/ Mineiro palmeirô que um dia vai voltar/ Mineiro palmeirô aqui tem um grande amigo/ Mineiro palmeirô que veio lá de Portugal/ Que é uma terra bem bonita/ Que um dia eu chego lá”. ${ }^{12}$ Neste caso, as canções vão sendo entoadas de improviso e à desgarrada: um canta fora da roda, outro responde dentro da roda. Infelizmente, o interesse dos Potiguara mais jovens por estas manifestações festivas em cantos e danças como é o coco deixaram de despertar curiosidade e assegurar adesão.

Dona Joana, por exemplo, lamenta que os jovens Potiguara dos nossos dias não se interessem por esta manifestação cultural, descriminando-a e, "embora saibam, não o querem e têm vergonha de o dançar". ${ }^{13}$ Depois de durante décadas ter servido para juntar e integrar os índios da reserva, dançadores e cantadores revelam-se magoados pela crescente perda de interesse da comunidade no coco, cada vez mais desprezado e depreciado. Trata-se de uma transformação que se encontra teorizada no trabalho de Maria e Marcos Ayala, recordando as funções de resistência política, social e cultural que se foram agregando ao coco, funcionalidades provavelmente esgotadas com as sucessivas transformações políticas do Brasil, estendendo-se da restauração da democracia à eleição recente da primeira mulher para a presidência brasileira, passando naturalmente pela governação assumidamente de esquerda e popular do presidente Luiz Inácio Lula da Silva:

Abrigados em outra dança, os cocos estariam driblando a repressão (ou, mais

\footnotetext{
${ }^{12}$ Canção gravada num ritual realizado na aldeia de Jacaré de César a 27 de Janeiro de 2006.

${ }^{13}$ Entrevista concedida por Dona Joana, a 6 de Dezembro de 2007, três meses antes de falecer.
} 
recentemente, a discriminação), recurso semelhante ao utilizado pelos rituais afro-brasileiros, que se desenvolviam sob a fachada do catolicismo (...) Pode-se afirmar que a brincadeira do coco é dança de minorias discriminadas, por diversas condições: pela etnia (negros, índios e seus descendentes), pela situação económica (pobreza, às vezes extrema), pela escolaridade (iletrados ou semi-alfabetizados), pelas profissões que exercem na sociedade (agricultores com pequenas propriedades ou sem terra, assentados rurais, pescadores, pedreiros, domésticas, copeiras de escolas). A dança passa por diferentes formas de interferência, qualquer que seja seu contexto, porque é difícil qualquer autonomia cultural numa região de forte controle político como o Nordeste, onde se aguçam as formas de dependência devido à pobreza extrema da população. ${ }^{14}$

Contrastando com as letras breves e repetitivas que se arrolam nas canções e rezas do toré, a poética do coco é consideravelmente mais rica, existindo uma variedade de formas com predominância para a redondilha de abundantes rimas, servindo temas que versam sobre a realidade do cantador, versos pitorescos, aspectos humorísticos, cómicos e insólitos. Por vezes a temática também aborda aspectos religiosos ou históricos.

Existe todavia uma notória falta de sentido material e factual nos versos do coco, recorrendo-se a metáforas em que predomina a temática amorosa, visitada em tom jocoso, mas também a frequência geralmente crítica do trabalho rural ou nas usinas de cana-de-açúcar. Com o improviso a ocupar lugar de destaque, os cocos têm inúmeras variações métricas, de estrofe e temáticas. As quadras são frequentemente divididas e fragmentadas pela intervenção dos elementos dos coros, apelidados de coristas, existindo dísticos, quadras e tercetos. Mesmo que sem muito rigor, a maior parte dos versos varia entre 5 e 7 sílabas, havendo outros mais longos ou mais curtos, nomeadamente rendidos a quadras cantadas em ritmo invariavelmente compassado. A forma dos versos intercalados é comum nas emboladas do coco dançado ${ }^{15}$ em que o coro repete sempre um mesmo verso e os solistas improvisam. Esta grande variação de formas denota a extrema liberdade deste género festivo, sobretudo em termos de manifestação poética, sendo de notar que, com alguma frequência, as quadras enfatizam esse ritmo ainda mais compassado, enquanto nas emboladas (os versos dos solistas intercalados com os do coro) a cadência é mais rápida ao ponto de, por vezes, ser difícil compreender as palavras de cantadores, imperando o ridículo, os insultos, o desrespeito, o grotesco, o gracejo, o impropério alternado frequentemente com a risada:

14 AYALA; AYALA, 2000, p. 37.

15 Os cantadores do coco dançado usam a terminologia "embolada" para definir um tipo de estrofe mais longa, intercalada com a "resposta" do coro. 
A ridicularização do companheiro; os insultos à mãe, ao pai, à irmã, à mulher, à família; o desrespeito a toda e qualquer ordem estabelecida; a zombaria e as ridicularizações dos contrastes sociais, acentuados para efeitos cómicos; a mundanização de valores sagrados através de hilariantes estórias de cunho moralizante; o apelo ao grotesco, ao fantástico, ao maravilhoso, ao exagero; o aproveitamento até mesmo de estereótipos sociais e raciais com fins humorísticos; tudo isso faz parte do riquíssimo universo temático da embolada, ao mesmo tempo em que a torna uma manifestação extremamente complexa, conforme já ressaltamos. E muito contribui para essa complexidade o facto de que, muitas vezes, ela não deixa de veicular também certa reprodução de estereótipos e conceitos dominantes, principalmente sociais e raciais, o que a torna ambígua sob muitos aspectos. ${ }^{16}$

Apesar das distâncias culturais e salvaguardados anacronismos históricos, as emboladas do coco possuem algumas semelhanças formais e funcionais com as cantigas ao desafio portuguesas, ainda hoje muito populares nas festividades do Norte de Portugal, espaço que, desde o século XVIII, haveria de alimentar a multiplicação da emigração portuguesa para o Brasil. Este cruzamento existe, todavia, limitado à produção das canções, na medida em que nas cantigas ao desafio não se dança e nos cocos isso acontece mesmo quando os dançadores não obedecem a regras ou padrões coreográficos fixos: a dança é geralmente livre, sendo o ritmo do corpo comandado pela batida e pela cadência dos versos. Tem razão o estudo que Ana Lúcia e Diógenes Maciel dirigiram ao coco em Forte Velho, sublinhando tratar-se de uma prática festiva em que "dança e poesia entrelaçam-se como duas faces de uma mesma moeda: enquanto a primeira contribui para a constituição dos versos, a poesia herda da dança as leis fundamentais para a sua organização". ${ }^{17}$

Apesar do coco acontecer sobretudo em momentos de festa, arrolam-se cocos para situações específicas, nomeadamente para acompanhar o trabalho agrícola ou industrial, atividades domésticos ou situações do dia-a-dia. Nestes casos mais ligados à sublimação individual e grupal da alienação doméstica ou laboral, encontram-se cocos cantando e dançando motivos religiosos saídos do catolicismo popular, homenageando santos populares, enquanto outros revisitam sujeitos e objetos da religiosidade tradicional, encontrando-se também, como no toré, cantigas a celebrar a jurema sagrada, mas já misturada ou no interior de temas e símbolos saídos tanto das festividades e cultos católicos quanto de outras

${ }^{16}$ AZEVEDO, Jimmy Vasconcelos. O Pandeiro e o Folheto: A Embolada Enquanto Manifestação Oral e Escrita. In: AYALA; AYALA, 2000, p. 85.

${ }^{17}$ LÚCIA, Ana Cristina Marinho; MACIEL, Diógenes André Vieira. O Coco em Forte Velho: Uma Poética Entre o Rio e o Canavia. In: AYALA, 2000, p. 108. 
manifestações religiosas normalmente classificadas como afro-brasileiras. ${ }^{18} \mathrm{~A}$ obra fundamental de Roger Bastide sobre as religiões africanas no Brasil interessou-se por estas transações culturais - hoje, diríamos transculturalidade (seja o que for que isto significa...) -, explicando com interesse que

sob a influência do espiritismo, às antigas divindades tupis vão reunir-se os espíritos dos mortos, dos catimbozeiros célebres, dos quais alguns eram negros; por outro lado, resta sempre uma margem de nostalgia ou de remorso na passagem de uma religião a outra; daí, os mestres africanos irem se integrar, no reino dos encantados, ao lado dos mestres caboclos e assim criar, a par com a "linha indígena", uma "linha africana. ${ }^{19}$

Estas relações, dialécticas e comunicações culturais parece evidenciarem-se especialmente nesses ritos e cultos a Jurema cantados tanto no toré como pelos diferentes cocos. Recorde-se novamente que no culto da jurema sagrada são utilizadas ervas, raízes e cascas de árvores que cumprem uma função mágica na cura, servindo também para afastar os males e recuperar as energias dos fiéis e participantes nos rituais e festividades. Entre os Potiguara, pajés e curandeiros especializaram-se na produção de bebidas a partir do que designam por jurema branca - em rigor, da casca da juremeira -, infusões que, supostamente, provocam sonhos afrodisíacos. Estes produtos encontram-se igualmente em rituais como o do catimbó nordestino, no candomblé do caboclo baiano, assim como no catimbó ou xangôs, rituais classificados como afro-brasileiros. Bastide procura explicar esta grande circulação de Jurema em várias religiosidades populares, concluindo que

podemos dizer, portanto, que o catimbó não passa da antiga festa da Jurema, que se modificou em contacto com o catolicismo, mas que, assim transformada, continuou a se manter nas populações mais ou menos caboclas, nas camadas inferiores da população do nordeste..$^{20}$

Importa, no entanto, esclarecer que estas sugeridas influências e cruzamentos culturais entre religiosidades dos indígenas brasileiros e as dos escravos africanos no Brasil são não apenas um legado do passado, mas muito mais uma propositada realidade contemporânea. Movimentos nativistas, antropólogos, folcloristas, políticos indígenas, políticos locais, políticos

${ }^{18}$ SILVA, Marinado José da; AYALA, Maria Ignez Novais. Da Brincadeira do Coco à Jurema Sagrada. In: AYALA; AYALA, 2000, p. 117.

${ }^{19}$ BASTIDE, Roger. As Religiões Africanas no Brasil. São Paulo: Pioneira, 1971, p. 250.

${ }^{20}$ BASTIDE, 1945, p. 205. 
nacionais e um sem número de outras organizações e pessoas foram nas últimas décadas aproximando politicamente os grupos e culturas marginalizados no passado, concorrendo para multiplicar revistas, jornais, festivais e incontáveis manifestações e encontros políticos em que se tornou obrigatório cruzar sonoridades indígenas e afro-brasileiras, dançá-las e mobilizá-las para a luta e reivindicação políticas. Não se encontram vestígios históricos e são escassas as provas antropológicas de uma qualquer influência afro-brasileira entre os Potiguara de ontem. Já quanto aos nossos Potiguara de hoje vêm a mesma televisão, ouvem as mesmas rádios e dançam os mesmo êxitos das músicas populares que circulam por todo o Brasil (e, em alguns casos, por todo o mundo). Não é, por isso, estranho que alguns cocos, cantados até por Dona Joana, misturem os mais diferentes cultos, nomes e símbolos: "Esse coco é meu/ É da Paraíba/ É de catolé/ é da macaíba/ Ô Lili, minha Lili”.

Apesar destas misturas, cruzamentos, confusões, juremas e excitações afro-brasileiras, a maioria dos cocos que se recolhe atualmente nas festas dos Potiguara são mais simples, muito mais telúricos e naturalistas, remetendo para o quotidiano das aldeias e do seu mundo envolvente de bichos e plantas. Assim, em Jacaré de São Domingos é especialmente popular este coco que canta o medo - para o esconjurar - das cobras:

Entrei na mata/ Ei caninana/ tirei meu imbé/ ei caninana/ a danada da cobra/ ei caninana/ mordeu o meu pé/ ei caninana/ é cobra verde/ ei caninana/ é cobra de corá/ ei caninana/ ela é siricucu/ ei caninana/ é cobra verde/ ei caninana/ é cobra de corá/ ei caninana/ ela é venenosa/ ei caninana/ ela vem me pegar/ ei caninana/ entrei na mata/ ei caninana. ${ }^{21}$

Esta coleção de vários motivos e temas naturalistas alimenta ainda o outro grande assunto dos cocos Potiguara: os jogos de amor. Neste caso, predomina essa lírica optimista cerzida por lugares, animais e pessoas perdidas entre a excitação e a expiação do amor: “Ô caninana/ da raiz da cana roxa/ não chore moça/ com pena de seu amor/ Agoadeira/ que agoa meu jardim/ deixou pra mim/ mais um lindo bloqué de flor" ${ }^{22}$

Quando se investiga em maior detalhe o sistema de circulação destas cantigas e orações que alimentam o toré e os cocos dos Potiguara, consegue perceber-se uma movimentação que praticamente deixou de se escorar em espaços tradicionais. Agora, as festas do calendário

${ }^{21}$ Coco registado na aldeia Potiguara de Jacaré de São Domingos a 8 de Janeiro de 2006.

${ }^{22}$ Coco registado na aldeia Potiguara de Jacaré de São Domingos a 8 de Janeiro de 2006. 
católico são mais importantes do que as perdidas reminiscências de festivais tradicionais. Estas festas somadas à escola e ao turismo tornaram-se as três estruturas e espaços fundamentais que organizam os lugares da memória dos Potiguara e a invenção das tradições locais.

\section{CONCLUSÃO}

Na mocejana deste artigo, no voo da narceja, ouve-se o trovão do pajé, como dizia Alencar, em Iracema, onde o rugido da terra é uma astúcia, como usavam os pajés e os sacerdotes de toda a nação para se imporem à imaginaçãa do povo. É precisamente a porangaba que nos faz reviver na memória e na visitação de todo o lugar dos Potiguara. Das crónicas do gavião branco, como chamava Batuireté ao guerreiro luso, plenas de conquistas e vitórias, clamando baptismos e conversões, narrando maravilhas e clamando por anseios de defesa dos índios, invertendo a profecia de tantos pajés em relação à destruição das nações “índias” pelos guerreiros brancos. Que não se consumaram, felizmente, conforme se pode avaliar neste estudo de carácter etno-histórico. A narceja potiguara continua a voar, no conhecimento do caminho que se faz em toda a ocasião, na marcha através do mangue, da floresta e das praias, nos campos ou no devir de toda a nação. Todo o índio é senhor do seu coaub, do seu caminho.

Um caminho que se continua a trilhar, nas festas da memória, nos rituais e nas vivências de um quotidiano que é acima de tudo uma marcha de vida. Uma pocema de um dia que não vai ficar nunca triste. O lugar onde canta a jandaia, a terra do índio. História, tradição, memória e futuro, são os eixos vectoriais deste trabalho, projectado no devir por via do turismo cultural cuidado e planeado, sem massas acéfalas e iconoclastas. Porque a memória jamais sucumbe neste jirau que nos leva rio fora, o rio da história nas suas águas pra bonançosas e de remanso suave, ora turbulentas e cheias de perigos. Sem lábios de mel como Iracema, mas com o esforço a que a ciência e o rigor nos impulsionam, este trabalho visa acima de tudo resgatar a memória. 